Pacific Journal of Mathematic 


\section{MAPPINGS AND DIMENSION IN GENERAL METRIC SPACES}

\section{JAMES KEESLING}

In this paper necessary and sufficient conditions are developed for certain classes of continuous functions $f(X)=Y$, where $X$ and $Y$ are arbitrary metric spaces, to have the property that $\operatorname{dim} K=\operatorname{dim} f(K)$ for all closed $K \subset X$. In particular it is shown that if $f$ is closed and $\operatorname{dim} f(K)>\operatorname{dim} K$ for some closed $K \subset X$, then there exists a closed $K^{\prime} \subset X$ so that $\operatorname{dim} K^{\prime}=0$ and $\operatorname{dim} f\left(K^{\prime}\right)>0$. These results are then used to show that if $f$ is closed and finite to one so that the multiplicity function of $f$ takes on at most $k+1$ distinct values, then $\operatorname{dim} K \leqq \operatorname{dim} f(K) \leqq \operatorname{dim} K+k$ for all closed $K \subset X$.

The purpose of this paper is to investigate the relation of the dimension of a closed subset of the domain with the dimension of its image in the range under various classes of continuous functions. In the first part of the paper we investigate this relation for closed subsets of the domain which have dimension zero. Using these results we characterize the property of being dimension preserving on closed subsets for a large class of mappings. In the second part of the paper we then show several important types of mappings to be dimension preserving on closed subsets. In the last section we generalize a result of Hurewicz [3]. The results of this paper are related to those of a number of investigators among whom are: Alexandroff [1], R. Hodel [2], K. Nagami [7], J. Nagata [8, pp. 68-73], J. H. Roberts [9], J. Suzuki [10], and R. F. Williams [11]. As indicated in the title, the setting for our study is the class of metric spaces.

Notation: Throughout the paper $X$ and $Y$ denote metric spaces and $f$ a continuous function from $X$ onto $Y$. By $\operatorname{dim} X$ is meant the Lebesgue covering dimension of $X$. This is, of course, equal to the large inductive dimension of $X$, denoted Ind $X$, in metric spaces. We let ind $X$ denote the small inductive dimension of $X$. The relation ind $X=$ Ind $X$ holds when $X$ is locally separable but not in general otherwise. The necessary background in dimension theory for general metric spaces (resp. separable metric spaces) will be found in J. Nagata [8] (resp. Hurewicz and Wallman [4]). Any additional hypotheses on $f, X$, or $Y$ will be explicitly stated in each theorem.

I. Closed $K \subset X$ with $\operatorname{dim} K=0$. We will need the following lemma several times throughout the paper. 
I.1. Lemma. Let $\operatorname{dim} X=n, n$ finite, and let $0 \leqq i \leqq n$. Then $\exists A, B$ so that $X=A \cup B$ with $\operatorname{dim} A=i, \operatorname{dim} B=n-i-1$, and with $A$ an $F_{\sigma}$ in $X$.

Proof. By the decomposition theorem ([8], p. 19) it is possible to find $A_{1}$ and $B_{1}$ so that $X=A_{1} \cup B_{1}$ with $\operatorname{dim} A_{1}=i$ and $\operatorname{dim} B_{1}=$ $n-i-1$. By Theorem II. 10, p. 32 [8] there exists $B \supset B_{1}$ with $B$ a $G_{\delta}$ in $X$ and $\operatorname{dim} B=n-i-1$. Let $A=X-B$. Then $A$ is an $F_{o}$ and $\operatorname{dim} A=i$.

I.2. Definition. Suppose for $f$ we have $X=\bigcup_{i=1}^{\infty} A_{i}, A_{i}$ closed in $X, f\left(A_{i}\right)$ closed in $Y$, and $f \mid A_{i}: A_{i} \rightarrow f\left(A_{i}\right)$ closed for all $i$. We say then that $f$ is $\sigma$-closed. These mappings arise naturally as (1) continuous mappings of $\sigma$-compact spaces, (2) finite to one open mappings, and (3) open mappings with discrete point inverses on separable metric spaces.

I.3. Lemma. $f$ is $\sigma$-closed if and only if $X=\bigcup_{i=1}^{\infty} A_{i}$ so that for each $i, A_{i}$ is an $F_{\sigma}$ in $X, f\left(A_{i}\right)$ is an $F_{\sigma}$ in $Y$ and $f \mid A_{i}: A_{i} \rightarrow f\left(A_{i}\right)$ is a closed mapping.

Proof. Suppose the latter condition holds. Then for each $i$ let $A_{i}=\bigcup_{k=1}^{\infty} F_{k, i}$ with each $F_{k, i}$ closed in $X$ and $F_{k, i} \subset F_{k+1, i}$ for all $k$. Likewise let $f\left(A_{i}\right)=\bigcup_{k=1}^{\infty} B_{k, i}$ with $B_{k, i}$ closed in $Y$ and $B_{k, i} \subset B_{k+1, i}$. Define $C_{k, i}=F_{k, i} \cap f^{-1}\left(B_{k, i}\right)$. Then one can easily verify that $X=$ $\mathbf{U}_{k, i} C_{k, i}$ satisfies the properties for $f$ to be $\sigma$-closed.

This characterization of $\sigma$-closed will be useful in showing certain mappings to be $\sigma$-closed. The next theorem is the fundamental result of this section.

I.4. THEOREM. Let $f$ be a closed mapping with $\operatorname{dim} X=n, 0 \leqq$ $n<\infty$, and $\operatorname{dim} Y \geqq k(n+1), 1 \leqq k<\infty$. Then there is a closed set $K \subset X$ with $\operatorname{dim} K=0$ and $\operatorname{dim} f(K) \geqq k$.

Proof. This is clearly true for $\operatorname{dim} X=0$. We proceed by induction. Suppose $\operatorname{dim} X=n>0$ and that the theorem holds for all lesser values of $n$. By Lemma I.1 we let $X=A \cup B$ with $A$ an $F_{\sigma}$, $\operatorname{dim} A=0$ and $\operatorname{dim} B=n-1$.

Case (i). $\quad \operatorname{dim} f(A) \geqq k$.

In this case let $A=\bigcup_{i=1}^{\infty} F_{i}$ with $F_{i}$ closed for all $i$. Since $f\left(F_{i}\right)$ is closed in $Y$ for all $i$, by the sum theorem for closed sets ([8], p. 17) there is an $i$ so that $\operatorname{dim} f\left(F_{i}\right) \geqq k$. Let $K=F_{i}$ in this case. 
Case (ii). $\operatorname{dim} f(A)<k$.

In this case let $C \supset f(A)$ in $Y$ with $C$ a $G_{\delta}$ and $\operatorname{dim} C=\operatorname{dim} f(A)<k$. Then $Y-C$ is an $F_{\sigma}$ and $\operatorname{dim}(Y-C) \geqq \operatorname{dim} Y-\operatorname{dim} C-1 \geqq k n$. Let $Y-C=\bigcup_{i=1}^{\infty} F_{i}$ so that each $F_{i}$ is closed. Then $\exists i$ so that $\operatorname{dim} F_{i} \geqq k n$. Since $f^{-1}\left(F_{i}\right) \leqq n-1$, apply our induction assumption to $f \mid f^{-1}\left(F_{i}\right)$ to complete the proof for this case.

I.5. COROLLARY. I.4 remains true if we replace $f$ closed with $f$ $\sigma$-closed.

I.6. Corollary. If $f$ is $\sigma$-closed and $K \subset X, K$ closed and $\operatorname{dim} K=$ $n, 0 \leqq n<\infty$, with $\operatorname{dim} f(K) \geqq k(n+1), 1 \leqq k<\infty$; then $\exists K^{\prime}$ closed, $K^{\prime} \subset K$ with $\operatorname{dim} K^{\prime}=0$ and $\operatorname{dim} f\left(K^{\prime}\right) \geqq k$.

1.7. Corollary. If $f$ is $\sigma$-closed and $f$ raises the dimension of any closed subset, then $f$ raises the dimension of a closed subset of dimension zero.

I.8. Definition. Let $f$ be such that for every closed set $K \subset X$, $\operatorname{dim} K=\operatorname{dim} f(K)$. Such a function will be said to be dimension preserving on closed subsets. If $\operatorname{dim} f^{-1}(y)=0$ for all $y \in Y$, then $f$ is said to be 0-dimensional.

The next theorem is due to Hurewicz who proved it for separable metric spaces. It has been proved for more general spaces including arbitrary metric spaces by K. Morita and K. Nagami. For a proof see Nagata [8, pp. 63-68].

I.9. Theorem. If $f$ is closed and $\operatorname{dim} X-\operatorname{dim} Y \geqq k \geqq 0$, then $\exists y \in Y$ so that $\operatorname{dim} f^{-1}(y) \geqq k$.

Clearly the theorem is true if we replace closed by $\sigma$-closed. We can therefore state the following characterization of dimension preserving on closed subsets for $\sigma$-closed mappings.

I.10. THEOREM. If $f$ is $\sigma$-closed, then $f$ is dimension preserving on closed subsets if and only if $f$ is 0-dimensional and has the property that $K \subset X, K$ closed, and $\operatorname{dim} K=0$ implies that

$$
\operatorname{dim} f(K)=0 \text {. }
$$

Proof. If $f$ lowered the dimension of some closed subset, by 1.9 $f$ would not be 0 -dimensional. If $f$ raised the dimension of some closed set, then it would raise the dimension of some closed set of dimension zero. 
Returning to I. 4 we now prove that if $X$ is Euclidean space, then we can improve the estimate given in I.4.

I.11. Theorem. Let $X=E^{n}$ and $\operatorname{dim} Y \geqq k n+1$ where $E^{n}$ denotes Euclidean $n$-space and $1 \leqq k<\infty$. Then $\exists K$ closed in $E^{n}$, $\operatorname{dim} K=0$ with $\operatorname{dim} f(K) \geqq k$.

Proof. Let $A$ be a countable dense set in $E^{n}$. Then since $f(A)$ is countable, it must have dimension zero. Let $B \supset f(A)$ be a $G_{o}$ so that $\operatorname{dim} B=0$. Then $\operatorname{dim}(Y-B) \geqq k n$ and $Y-B$ is an $F_{\sigma}$. Let $Y-B=\bigcup_{i=1}^{\infty} F_{i}$ be a countable union of closed sets. Let $\operatorname{dim} F_{i} \geqq k n$. Since $f^{-1}\left(F_{i}\right) \subset E^{n}-A, f^{-1}\left(F_{i}\right)$ has no interior points and $\operatorname{dim} f^{-1}\left(F_{i}\right) \leqq$ $n-1$. Now $f \mid f^{-1}\left(F_{i}\right)$ is $\sigma$-closed since $E^{n}$ is $\sigma$-compact. The proof is now completed by applying I.5 to $f \mid f^{-1}\left(F_{\imath}\right)$.

I.12. Corollary. If $X=E^{1}$ and $\operatorname{dim} Y=m>1$, then $\exists K$ closed in $X, \operatorname{dim} K=0$ with $\operatorname{dim} f(K) \geqq m-1$.

The concluding theorem of this section is for an arbitrary continuous function which lowers dimension.

I.13. THEOREM. Let $\operatorname{dim} Y=n$ and $\operatorname{dim} X \geqq k(n+1)$ where $0 \leqq$ $n<\infty$ and $1 \leqq k<\infty$; then $\exists K \subset X, K$ closed, $\operatorname{dim} K \geqq k$ with $\operatorname{dim} f(K)=0$.

Proof. By induction on $n$. In case $n=0$, let $K=X$. Let $\operatorname{dim} Y=n>0$ and suppose the theorem is true for all lesser values of $n$. Let $Y=A \cup B$ with $A$ an $F_{\sigma}, \operatorname{dim} A=0$ and $\operatorname{dim} B=n-1$. We then have two cases.

Case (i). $\operatorname{dim} f^{-1}(A) \geqq k$.

In this case let $A=\bigcup_{i=1}^{\infty} F_{i}$ closed and get an $i$ so that

$$
\operatorname{dim} f^{-1}\left(F_{i}\right) \geqq k \text {. }
$$

Case (ii). $\operatorname{dim} f^{-1}(A)<k$.

Then let $C \supset f^{-1}(A)$ be a $G_{o}$ so that $\operatorname{dim} C=\operatorname{dim} f^{-1}(A)<k$. Then $\operatorname{dim}(X-C) \geqq k n$. Let $X-C=\bigcup_{i=1}^{\infty} F_{i}$ where each $F_{i}$ is closed in $X$. Then $\exists i$ so that $\operatorname{dim} F_{i} \geqq k n$. Since $f\left(F_{i}\right) \subset B, \operatorname{dim} f\left(F_{i}\right) \leqq n-1$. We now apply our induction assumption to $f \mid F_{i}$ and theorem follows.

1.14. Corollary. If $f$ lowers the dimension of any closed set of the domain, then $f$ takes a closed set of positive dimension onto a set of dimension zero. 
II. Functions dimension preserving on closed subsets. In this section we will show the following types of functions to be dimension preserving on closed subsets and $\sigma$-closed: (1) $f$ open with $f^{-1}(y)$ discrete with $X$ separable; (2) $f$ finite to one and open; (3) $f \sigma$-closed, open, $f^{-1}(y)$ discrete for all $y \in Y$; (4) $f \sigma$-closed and exactly $k$ to one. We will first prove (3) and then show that (1) and (2) follow. We will then show that (4) is a result of (2). Some examples and other theorems will be inserted at appropriate points in this chain of argument.

II.1. THEOREM. Let $f$ be open with $f^{-1}(y)$ discrete for all $y \in Y$. Then for all $K \subset X, \operatorname{dim} K \leqq \operatorname{dim} f(K)$.

Proof. Let $\left\{A_{\alpha, n}: \alpha \in \Gamma_{n}\right\}$ be a locally finite open cover of $X$ so that $\operatorname{diam}\left(A_{\alpha, n}\right) \leqq 1 / n$ for all $\alpha \in \Gamma_{n}$. Let $B_{\alpha, n}=\left\{x \in A_{\alpha, n}: f^{-1} f(x) \cap A_{\alpha, n}=x\right\}$. By the openness of $f, B_{\alpha, n}$ is closed in $A_{\alpha, n}$ as is $f\left(B_{\alpha, n}\right)$ in $f\left(A_{\alpha, n}\right)$. Therefore $B_{\alpha, n}$ and $f\left(B_{\alpha, n}\right)$ are $F_{\sigma}^{\prime} s$. It is easily seen that

$$
f \mid B_{\alpha, n}: B_{\alpha, n} \rightarrow f\left(B_{\alpha, n}\right)
$$

is open. Since it is also one to one and continuous, it is a homeomorphism. Therefore $\operatorname{dim} K \cap B_{\alpha, n}=\operatorname{dim} f\left(K \cap B_{\alpha, n}\right)$ for all $n$ and all $\alpha \in \Gamma_{n}$. By the sum theorem, $\exists B_{\alpha, n}$ so that $\operatorname{dim} K \cap B_{\alpha, n} \geqq k$ if $\operatorname{dim} K \geqq k$, noting that $\bigcup_{\alpha, n} B_{\alpha, n}=X$ is $\sigma$-locally finite. But then $\operatorname{dim} f(K) \geqq k$.

II.2. Example. Let $I$ be the unit interval $[0,1]$ in $E^{1}$ with the ordinary topology and let $I^{*}$ be the same set with the discrete topology. Define $f: I \times I^{*} \rightarrow I$ so that $f(a, b)=a$. Then $f$ is open and $f^{-1}(y)$ is discrete for all $y$. Let $\Delta=\{(a, a): a \in I\} \subset I \times I^{*}$. Then $\Delta$ is discrete and closed, hence $\operatorname{dim} \Delta=0$. But $f(\Delta)=I$. Therefore we cannot prove equality in II. 1 even for closed $K$ in $X$ without additional assumptions on $f$.

II.3. THEOREM. If $f$ is open, $\sigma$-closed, and $f^{-1}(y)$ is discrete for all $y \in Y$, then $f$ is dimension preserving on closed subsets.

Proof. Since $f$ is 0-dimensional we need only show that the second condition of $\mathrm{I} .10$ holds. Let $\mathrm{K} \subset X$ with $\operatorname{dim} K=0$ and $K$ closed and suppose $\operatorname{dim} f(K)>0$. We may assume $K \subset A_{i}$ for some $i$ where $X=\bigcup_{j=1}^{\infty} A_{j}$ as in the definition of $\sigma$-closed. Let $\left\{A_{\alpha, n}: \alpha \in \Gamma_{n}\right\}$ be a locally finite open cover of $X$ with $\operatorname{diam}\left(A_{\alpha, n}\right) \leqq 1 / n$. Let $F_{\alpha, n} \subset A_{\alpha, n}$ so that $\left\{F_{\alpha, n}: \alpha \in \Gamma_{n}\right\}$ forms a closed cover of $X$. Let 


$$
Q_{\alpha, n}=\left\{x \in F_{\alpha, n} \cap K: f^{-1} f(x) \cap A_{\alpha, n}=x\right\} .
$$

Then $Q_{\alpha, n}$ is closed in $X$ by the openness of $f$. Now $\left\{Q_{\alpha, n}: \alpha \in \Gamma_{n}\right\}$ is locally finite, hence closure preserving. Since $Q_{\alpha, n} \subset A_{i}$ and $f \mid A_{i}$ is closed we get that $\left\{f\left(Q_{\alpha, n}\right): \alpha \in \Gamma_{n}\right\}$ is closure preserving in $Y$. By a theorem due to Nagami ([8], p. 18) we have that if $\operatorname{dim} f\left(Q_{\alpha, n}\right) \leqq k$ for all $\alpha \in \Gamma_{n}$, then $\operatorname{dim} \bigcup_{\alpha} f\left(Q_{\alpha, n}\right) \leqq k$. Now $f \mid Q_{\alpha, n}$ is a homeomorphism onto $f\left(Q_{\alpha, n}\right)$, hence $\operatorname{dim} f\left(Q_{\alpha, n}\right) \leqq 0$. Now $B_{n}=\mathbf{U}_{\alpha \in \Gamma_{n}} f\left(Q_{\alpha, n}\right)$ is closed with $\operatorname{dim} B_{n}=0$. We can easily verify that $\bigcup_{n=1}^{\infty} B_{n}=f(K)$. Therefore $\operatorname{dim} f(K)=0$, a contradiction of our assumption that $\operatorname{dim} f(K)>0$. That is, $f$ must be dimension preserving on closed subsets.

II.4. THEOREM. If $f$ is open with discrete point inverses and $X$ is separable, then $f$ is dimension preserving on closed subsets.

Proof. Let $\left\{A_{i}\right\}$ be a countable basis for $X$. Let

$$
B_{i}=\left\{x \in A_{i}: f^{-1} f(x) \cap A_{i}=x\right\} .
$$

Then $B_{i}$ is an $F_{\sigma}$ as is $f\left(B_{i}\right)$. Now $f \mid B_{i}$ is a homeomorphism onto $f\left(B_{i}\right)$. Applying I.3 we get that $f$ is $\sigma$-closed. Applying II.3 we get that $f$ is dimension preserving on closed subsets.

II.5. Note. If we actually apply the proof of I.3 to this case we get $X=\bigcup_{i=1}^{\infty} A_{i}, A_{i}$ closed, $f\left(A_{i}\right)$ closed, with $f \mid A_{i}$ a homeomorphism onto $f\left(A_{i}\right)$.

II.6. Lemma. If $f$ is open and exactly $k$ to one, then $f$ is closed.

Proof. Let $y_{n} \rightarrow y$ be a sequence of distinct points in $Y$. Let $x_{n} \in f^{-1}\left(y_{n}\right)$ for all $n$ and suppose that $\left\{x_{n}\right\}$ has no limit point in $X$. Then we may choose $\left\{V_{i}\right\}_{i=1}^{k}$ a disjoint collection of open sets, each containing no point of the set $\left\{x_{n}\right\}$ where $z_{i} \in V_{i}$ and $f^{-1}(y)=\left\{z_{1}, \cdots, z_{k}\right\}$. By the openness of $f, \exists N_{i}$ such that $n \geqq N_{i}$ implies that $f^{-1}\left(y_{n}\right) \cap V_{i} \neq \Phi$. Let $N=\max \left\{N_{i}\right\}_{i=1}^{k}$. Then $f^{-1}\left(y_{N}\right) \cap V_{i} \neq \Phi$ for all $i$. But $f^{-1}\left(y_{N}\right)$ consists of exactly $k$ points. Therefore there is exactly one point of $f^{-1}\left(y_{N}\right)$ in each $V_{i}$ and every point is in one of the $V_{i}^{\prime} s$. Therefore $x_{N} \in V_{i}$ for some $i$, a contradiction. Therefore the sequence $\left\{x_{n}\right\}$ must have some convergent subsequence and $f$ must be closed.

II.7. THEOREM. If $f$ is open and finite to one, then $f$ is dimension preserving on closed subsets.

Proof. Let $Y_{k}=\left\{y \in Y: f^{-1}(y)\right.$ has $k$ or more points $\}$. Let $\mu(y)$ be the number of points in $f^{-1}(y)$. Since $f$ is open, $\mu$ is lower semi- 
continuous. Therefore $Y_{k}$ is open for all $k$. Therefore

$$
B_{k}=Y_{k} \cap\left(Y-Y_{k+1}\right)
$$

is an open set intersected with a closed set, hence is an $F_{\sigma}$. But $B_{k}=\{y: \mu(y)=k\}$. Therefore $f \mid f^{-1}\left(B_{k}\right)$ is closed onto $B_{k}$ by II.6 since an open function restricted to an inverse set is open onto its image. Applying I.3 and II.3 we have that $f$ is dimension preserving on closed subsets.

II.8. THEOREM. If $f$ is closed and exactly $k$ to one, then $f$ is dimension preserving on closed subsets.

Proof. Let $y \in Y$ and let $f^{-1}(y)=\left\{x_{1}, \cdots, x_{k}\right\}$. If $k=1$, then $f$ is a homeomorphism. Suppose $k>1$ and define

$$
\Sigma_{y}=\min \left\{d\left(x_{i}, x_{j}\right): x_{i} \neq x_{j}\right\} .
$$

Then $\Sigma_{y}>0$ for all $y \in Y$. Using the closedness of $f$ it is possible to show that if $A_{n}=\left\{y \in Y: \Sigma_{y} \geqq 1 / n\right\}$, then $A_{n}$ is closed in $Y$ and $f \mid f^{-1}\left(A_{n}\right)$ onto $A_{n}$ is open. Thus $f$ is dimension preserving on closed subsets by II.7.

II.9. THEOREM. If $f$ is $\sigma$-closed and exactly $k$ to one, then $f$ is dimension preserving on closed subsets.

Proof. Let $X=\bigcup_{i=1}^{\infty} A_{i}$ as in the definition of $\sigma$-closed. We may assume $A_{i} \subset A_{i+1}$ for all $i$. Let $B_{i}=\left\{x \in A_{i}: f^{-1} f(x) \subset A_{i}\right\}$. Then $f\left(B_{i}\right)=\left\{y \in f\left(A_{i}\right): \mu_{i}(y)=\max \mu_{i}\right\}$ where $\mu_{i}(y)$ is the number of points in $f^{-1}(y) \cap A_{i}$. If we define $\Sigma_{y}=\min \left\{d\left(x_{i}, x_{j}\right) ; x_{i} \neq x_{j}\right\}$ where $f^{-1}(y)=$ $\left\{x_{1}, \cdots, x_{k}\right\}$ and then define $C_{n}=\left\{y \in f\left(A_{i}\right): y \in f\left(B_{i}\right)\right.$ and $\left.\Sigma_{y} \geqq 1 / n\right\}$. Then using the closedness of $f \mid A_{i}, C_{n}$ will be a closed set in $Y$. But $f\left(B_{i}\right)=\bigcup_{n=1}^{\infty} C_{n}$. Therefore $f\left(B_{i}\right)$ is an $F_{\sigma}$ and since $f^{-1} f\left(B_{i}\right)=B_{i}, B_{i}$ is also an $F_{\sigma}$. Now if $x \in X$, then since $f^{-1} f(x)$ is finite, $\exists A_{i}$ so that $f^{-1} f(x) \subset A_{i}$. Therefore $x \in B_{i}$ and $\bigcup_{i=1}^{\infty} B_{i}=X$. Now $f \mid B_{i}$ is closed onto $f\left(B_{i}\right)$ since $B_{i}$ is an inverse set in a set on which $f$ is closed. Since $f \mid B_{i}$ is exactly $k$ to one, $f \mid B_{i}$ is dimension preserving on closed subsets. Thus $f$ is dimension preserving on closed subsets. Thus $f$ is dimension preserving on closed subsets on all of $X$ by the sum theorem.

II.10. CoRollary. If $f$ is $\sigma$-closed and exactly $k$ to one except for a set $B \subset Y$ which is an $F_{\sigma}$ with $\operatorname{dim} B=0$ and $f^{-1}(y)$ has less than $k$ points for all $y \in B$, then $f$ is dimension preserving on closed subsets. 
Proof. Let $C_{n}=\left\{y \in Y-B: \Sigma_{y} \geqq 1 / n\right\}$. Then by the $\sigma$-closedness of $f, C_{n}$ is an $F_{\sigma}$. Now $f \mid f^{-1}\left(C_{n}\right)$ is $\sigma$-closed onto $C_{n}$ and exactly $k$ to one, therefore dimension preserving on closed subsets. Now if $K \subset X, K$ closed with $\operatorname{dim} K=0$ and $\operatorname{dim} f(K)>0$, then

$$
\operatorname{dim} f(K) \cap B>0 \text {. }
$$

But by assumption $\operatorname{dim} B=0$. Therefore $\operatorname{dim} f(K)=0$ and $f$ is dimension preserving on closed subsets.

II.11. ExAmple. Let $I$ be the unit interval and $C$ the Cantor ternary set. Let $f: C \rightarrow I$ be the cantor ternary function onto the interval. Then $f$ is one to one except for a countable set $B \subset I$. However, for $y \in B, f^{-1}(y)$ has two points. Therefore our assumption that $f^{-1}(y)$ have fewer than $k$ points in II.10 was not superfluous.

III. Closed $K \subset X$ with $\operatorname{dim} K<\operatorname{dim} f(K)$. The results which motivated the theorems of this section are due mainly to Hurewicz [3]. His basic result is the following.

III. 1. THEOREM. Let $f$ be closed and finite to one with $X$ and $Y$ separable metric spaces. Then if $\operatorname{dim} Y-\operatorname{dim} X \geqq k \geqq 0$, then $\mu$ takes on at least $k+1$ distinct values, where $\mu(y)$ is the number of points in $f^{-1}(y)$.

Apparently there has been some difficulty in generalizing this result to arbitrary metric spaces since the statement in J. Nagata [8, p. 68] leaves out a considerable amount of the force of III.1. Also his statement of Suzuki's result (footnote p. 73 [8]) is again only a partial result. Our results in this section will imply the full force of III.1 in arbitrary metric spaces and will be considerably more general. Our basic result is III.2.

III.2. THEOREM. If $f$ is $\sigma$-closed and finite to one and if $K \subset X$ is closed with $\operatorname{dim} f(K)-\operatorname{dim} K \geqq k \geqq 0$, then $\mu$ takes on at least $k+1$ values on $f(K)$.

We will need a sequence of lemmas before we can prove III.2.

III.3 Lemma. Let $\operatorname{dim} X=n$ and $A \subset X$ be an $F_{o}$ so that

$$
\operatorname{dim} A \leqq n-1 \text {. }
$$

Then there is an $N \subset X-A, N$ an $F_{o}$, with $\operatorname{dim} N=0$ and

$$
\operatorname{dim}(X-N)=n-1 \text {. }
$$


Proof. Let $X=B \cup C$ with $B$ an $F_{\sigma}, \operatorname{dim} B=n-1$ and $\operatorname{dim} C=$ 0 . Then $A \cup B$ is the union of two $F_{o}$ 's each of dimension less than n. Therefore $\operatorname{dim}(A \cup B)=n-1$. Let $D \supset A \cup B$ be a $G_{\delta}$ with $\operatorname{dim} D=n-1$. Let $N=X-D$. Then $\operatorname{dim} N=0$ since $N \subset C$. Clearly $N$ has the other required properties.

III.4. Lemma. Let $f$ be $\sigma$-closed and finite to one. Let $Y_{m}=$ $\{y \in Y: \mu(y) \geqq m\}$. Then $Y_{m}$ is an $F_{\sigma}$ in $Y$.

Proof. Let $X=\bigcup_{i=1}^{\infty} A_{i}$ be as in the definition of $\sigma$-closed. We may suppose that $A_{i} \subset A_{i+1}$. It is sufficient to show that

$$
B_{i}=\left\{y \in Y_{m}: f^{-1}(y) \subset A_{i}\right\}
$$

is an $F_{o}$ for all $i$. Let $C_{n}=\left\{y \in Y_{m} \cap f\left(A^{i}\right): \exists\left\{x_{1}, \cdots, x_{m}\right\} \subset f^{-1}(y) \cap A_{i}\right.$ so that $d\left(x_{i}, x_{j}\right) \geqq 1 / n$ for $\left.i \neq j\right\}$. Then using the closedness of $f$ on $A_{i}$, it is possible to show that $C_{n}$ is closed in $A_{i}$ for all $n$. But $\mathrm{U}_{n=1}^{\infty} \mathrm{C}_{n}=B_{i}$. Therefore $Y_{m}$ is an $F_{\sigma}$ as asserted.

III.5. Theorem. Suppose $f$ is $\sigma$-closed and finite to one. Let $Y_{k}=\{y \in Y: \mu(y) \geqq k)$. Let $m=\min \{\mu(y): y \in Y\}$. Then if $K \subset X$ is closed with $\operatorname{dim} K \leqq n$ and $\operatorname{dim}\left[f(K) \cap Y_{m+1}\right]<n$, then $\operatorname{dim} f(K) \leqq n$.

Proof. Let $K$ satisfy the hypotheses of the theorem. We may assume $n$ to be finite. If $n=0$, then $\operatorname{dim}\left[f(K) \cap Y_{m+1}\right]<0$ means that $f(K) \cap Y_{m+1}=\Phi$. Therefore $K \subset f^{-1}\left(Y_{m}-Y_{m+1}\right)$. By II.9 $\operatorname{dim} f(K) \leqq$ 0 . Now let $n>0$ and suppose that the theorem holds for lesser values of $n$. By the hypothesis $\operatorname{dim}\left[f(K) \cap Y_{m+1}\right] \leqq n-1$. Since $f$ is 0-dimensional we have $\operatorname{dim}\left[f^{-1}\left(f(K) \cap Y_{m+1}\right) \cap K\right] \leqq n-1$. Let $A=f^{-1}\left(f(K) \cap Y_{m+1}\right) \cap K$. Then $A$ is an $F_{\sigma}$ in $K$ by III.4. By III.3 let $N \subset K-A$ be an $F_{\sigma}$ so that $\operatorname{dim} N \leqq 0$ and $\operatorname{dim}(K-N) \leqq n-1$. Then $N \subset f^{-1}\left(Y_{m}-Y_{m+1}\right)$. Since $f$ is dimension preserving on closed subsets on $f^{-1}\left(Y_{m}-Y_{m+1}\right), \operatorname{dim} f(N) \leqq 0$. Since $f$ is $\sigma$-closed, $f(N)$ is also an $F_{\sigma}$. Let $N^{\prime} \subset Y_{m+1} \cap f(K)$ so that $N^{\prime}$ is an $F_{\sigma}$ in $Y_{m+1} \cap f(K)$, $\operatorname{dim} N^{\prime} \leqq 0$ and so that $\operatorname{dim}\left[Y_{m+1} \cap f(K)-N^{\prime}\right] \leqq n-2$. Note that $N^{\prime}$ is also an $F_{\sigma}$ in $Y$, since $f(K)$ and $Y_{m+1}$ are both $F_{\sigma}$ 's. Now let:

$$
\begin{aligned}
Y^{\prime} & =f(K)-N^{\prime} \cup f(N) \\
K^{\prime} & =f^{-1}\left(Y^{\prime}\right) \cap K .
\end{aligned}
$$

Then $f\left(K^{\prime}\right)=Y^{\prime}$. We also have;

$$
\operatorname{dim}\left[Y^{\prime} \cap Y_{m+1}\right]=\operatorname{dim}\left[f(K) \cap Y_{m+1}-N^{\prime}\right]<n-1 .
$$

Now $K^{\prime} \subset K-N$ and therefore $\operatorname{dim} K^{\prime} \leqq n-1$. Observing that $f \mid f^{-1}\left(Y^{\prime}\right)$ onto $Y^{\prime}$ is $\sigma$-closed and $K^{\prime}$ is closed in $f^{-1}\left(Y^{\prime}\right)$ we can apply 
our induction assumption to get $\operatorname{dim} f\left(K^{\prime}\right)=\operatorname{dim} Y^{\prime} \leqq n-1$. Let $M=$ $f(K)-Y^{\prime}$. Then $M=f(N) \cup N^{\prime}$ and since $f(N)$ and $N^{\prime}$ are both $F_{\sigma}$ 's, $\operatorname{dim} M \leqq 0$. By the sum theorem, $\operatorname{dim} f(K) \leqq \operatorname{dim} Y^{\prime}+\operatorname{dim} M+1 \leqq n$.

III.6. Corollary. If $f$ is $\sigma$-closed and finite to one and $K \subset X$ is closed with $\operatorname{dim} f(K)>\operatorname{dim} K$, then if $m=\min \{\mu(y): y \in f(K)\}$, then $\operatorname{dim}\left[f(K) \cap Y_{m+1}\right] \geqq \operatorname{dim} f(K)-1$.

\section{Proof. In III.5 let $n=\operatorname{dim} f(K)-1$.}

Proof of III.2. We simply apply III.6 inductively in the following manner. Let $m_{1}=\min \{\mu(y): y \in f(K)\}$. Then if $k=0$ we are finished. Suppose $k>0$. Then by III. 6 we get that

$$
\operatorname{dim}\left[f(K) \cap Y_{m_{1}+1}\right] \geqq \operatorname{dim} f(K)-1 \geqq 0 .
$$

Let $m_{2}=\min \left\{\mu(y): y \in f(K) \cap Y_{m_{1}+1}\right\}$. Then $m_{2}>m_{1}$ and $\mu$ takes on the value $m_{2}$ on $f(K)$. Let $K^{\prime}=K \cap f^{-1}\left(Y_{m_{1}+1}\right)$ which is closed in $f^{-1}\left(f(K) \cap Y_{m_{1}+1}\right)$. Since $f$ restricted to this latter set is $\sigma$-closed we now can say that if $k-1>0$, then $\operatorname{dim} f\left(K^{\prime}\right)-\operatorname{dim} K^{\prime} \geqq k-1>0$ and we can repeat the above process for $K^{\prime}$ to get an

$$
m_{3}=\min \left\{\mu(y): y \in f\left(K^{\prime}\right) \cap Y_{m_{2}+1}\right\} \text {. }
$$

We can continue this process until $k-i=0$, that is, at least $k$ times to get a sequence $\left\{m_{1}<\cdots<m_{k+1}\right\}$ with $\mu\left(y_{i}\right)=m_{i}$ for some $y_{i} \in f(K)$ for each $i \leqq k+1$.

III.7. THEOREM. If $f$ is $\sigma$-closed and $K \subset X$ is closed and locally Euclidean with $\operatorname{dim} f(K)-\operatorname{dim} K \geqq k>0$ then $\mu$ takes on at least $k+2$ distinct values in $f(K)$.

Proof. Since $K$ is locally Euclidean in the subspace topology it must be locally separable and hence ind $K=\operatorname{dim} K$. Therefore $\operatorname{dim} \mathrm{K}=$ $\sup \{n: K$ contains a Euclidean neighborhood of dimension $n\}$. Let us assume $\mu$ takes on a finite number of values on $f(K)$. Let $m=$ $\max \{\mu(y): y \in f(K)\}$ and let $B=\operatorname{int}_{K}\left(f^{-1}\left(Y_{m}\right) \cap K\right)$ be the interior in $K$ of $f^{-1}\left(Y_{m}\right) \cap K$. Since $B$ is open in $K$ which is closed in $X, K$ must be an $F_{\sigma}$ in $X$. Since $B \subset f^{-1}\left(Y_{m}-Y_{m+1}\right), \operatorname{dim} f(B)=\operatorname{dim} B \leqq \operatorname{dim} K$. Let $K^{\prime}=K-B$. Then $K^{\prime}$ is closed. Now $f(K)=f\left(K^{\prime}\right) \cup f(B)$ is the union of two $F_{o}$ 's. Therefore

$$
\operatorname{dim} f(K)=\max \left\{\operatorname{dim} f\left(K^{\prime}\right), \operatorname{dim} f(B)\right\}=\operatorname{dim} f\left(K^{\prime}\right) .
$$

We now have two cases: 
Case (i). $f^{-1}\left(Y_{m}\right) \cap K^{\prime}=\Phi$.

In this case $\mu$ takes on at least $k+1$ values on $f\left(K^{\prime}\right)$. It also takes on the additional value $m$ which makes $k+2$ values.

Case (ii). $f^{-1}\left(Y_{m}\right) \cap K^{\prime} \neq \Phi$.

In this case we repeat the construction of $\left\{m_{1}<\cdots<m_{k+1}\right\}$ as in III.2 on $f\left(K^{\prime}\right)$. But simply note that for $m=\max \left\{\mu(y): y \in f\left(K^{\prime}\right)\right\}$, $f^{-1}\left(Y_{m}\right) \cap K^{\prime}$ has no interior points in $K$. Therefore

$$
\operatorname{dim}\left[f^{-1}\left(Y_{m}\right) \cap K^{\prime}\right]<\operatorname{dim} K,
$$

so we can continue the construction one more step to get a sequence $\left\{m_{1}<\cdots<m_{k+2}\right\}$.

The last result shows that it is possible to generalize these results to $\sigma$-closed functions with $\operatorname{Fr}\left(f^{-1}(y)\right)$ finite for all $y \in Y$.

III.8. THEOREM. Let $f$ be $\sigma$-closed with $\operatorname{Fr}\left(f^{-1}(y)\right)$ finite for all $y \in Y$; then if $K \subset X$ is closed with $\operatorname{dim} f(K)-\operatorname{dim} K \geqq k>0$, then if we let $X_{m}=\bigcup\left\{F r\left(f^{-1}(y)\right): F r\left(f^{-1}(y)\right)\right.$ has exactly $m$ points $\}$, then $K \cap X_{m} \neq \Phi$ for at least $k+1$ distinct $m$ 's.

Proof. We note that $\bigcup_{m=1}^{\infty} X_{m}=X-\bigcup_{y \in Y} \operatorname{int}\left(f^{-1}(y)\right)$ and consequently $\bigcup_{m=1}^{\infty} X_{m}$ is closed. Therefore $f$ restricted to this set is $\sigma$ closed and finite to one. If $A=f(K)-f\left(K \cap\left(\bigcup X_{m}\right)\right)$ then by the $\sigma$-closedness of $f, A$ is the countable union of closed discrete sets, therefore $A$ is an $F_{\sigma}$ of dimension zero. Since $\operatorname{dim} f(K)>0$, we must have $\operatorname{dim} f(K)=\operatorname{dim} f\left(K \cap\left(\bigcup X_{m}\right)\right)$. Applying III.2 to $K \cap\left(\cup X_{m}\right)$ we get that $K \cap X_{m} \neq \Phi$ for at least $k+1$ distinct $m$ 's.

III.9. Theorem. If $K$ is locally Euclidean in III.8, then we can replace $k+1$ by $k+2$.

Proof. Combining the proofs of III.7 and III.8 with slight modification will yield III.9.

IV. Final remarks. One may have in mind to generalize the results contained in this paper to arbitrary sets without restricting them to be closed. The following example serves to indicate that without strong conditions on the function the prospects are not promising.

IV.1. ExAmple. Let $X=\left\{(x, y) \in E^{2} ; 0 \leqq x \leqq 1\right.$ and $y=0$ or $y=$ 1). Let $f: X \rightarrow[0,1]$ so that $f(x, y)=x$. Then $f$ is open and closed and two to one. Let $A$ be the rationals in $[0,1]$ and $B$ the irrationals in $[0,1]$. Let $K=\{0\} \times A \cup\{1\} \times B$. Then $\operatorname{dim} K=0$ and 


$$
\operatorname{dim} f(K)=1
$$

Once one has this example in mind he will likely be able to construct a variety of other examples. This indicates how important our assumption was that the sets be closed.

The author wishes to thank Professor Edwin Duda for his patient encouragement in directing this research.

\section{BIBLIOGRAPHY}

1. P. Alexandroff, Uber abzählbar-fache offene Abbildungen, C. R. (Doklady) Acad. Sci. USSR 4 (1936).

2. R. Hodel, Open functions and dimension, Duke Math. J. 30 (1963), 461-467.

3. Hurewicz, Uber dimensionserhöhende stetige Abbildungen, J. Reine u. Angew. Math. 169 (1933), 71-78.

4. - Wallman, Dimension Theory, Princeton, 1941.

5. J. Kelley, General Topology, Van Nostrand, 1955.

6. C. Kuratowski, Topologie II, Warszawa, 1950.

7. K. Nagami, Mappings of finite order and dimension theory, Japan. J. Math. 30 (1950), 25-54.

8. J. Nagata, Modern Dimension Theory, John Wiley, 1965.

9. J. Roberts, Open transformations and dimension, Bull. Amer. Math. Soc. 53 (1947), 176-178.

10. J. Suzuki, Note on a theorem for dimension, Proc. Japan Acad. 35 (1959), 201-202.

11. R. Williams, The effect of maps upon the dimension of subsets of the domain space, Proc. Amer. Math. Soc. 8 (1957), 580-583.

Received May 19, 1967. The results in this paper will form a part of the author's doctoral dissertation. The author holds a NASA predoctoral fellowship at the University of Miami. The results of this paper were presented to the American Mathematical Society April 8, 1967. 


\section{PACIFIC JOURNAL OF MATHEMATICS}

\section{EDITORS}

\section{H. ROYDEN}

Stanford University

Stanford, California
J. DugundJI

Department of Mathematics

Rice University

Houston, Texas 77001

RICHARD ARENS

University of California

Los Angeles, California 90024

Seattle, Washington 98105

\section{ASSOCIATE EDITORS}
E. F. BeCKENBACH
B. H. NeumanN
F. WOLF
K. YOSIDA

\section{SUPPORTING INSTITUTIONS}

\author{
UNIVERSITY OF BRITISH COLUMBIA \\ CALIFORNIA INSTITUTE OF TECHNOLOGY \\ UNIVERSITY OF CALIFORNIA \\ MONTANA STATE UNIVERSITY \\ UNIVERSITY OF NEVADA \\ NEW MEXICO STATE UNIVERSITY \\ OREGON STATE UNIVERSITY \\ UNIVERSITY OF OREGON \\ OSAKA UNIVERSITY \\ UNIVERSITY OF SOUTHERN CALIFORNIA
}

\author{
STANFORD UNIVERSITY \\ UNIVERSITY OF TOKYO \\ UNIVERSITY OF UTAH \\ WASHINGTON STATE UNIVERSITY \\ UNIVERSITY OF WASHINGTON \\ * * * * \\ AMERICAN MATHEMATICAL SOCIETY \\ CHEVRON RESEARCH CORPORATION \\ TRW SYSTEMS \\ NAVAL WEAPONS CENTER
}

Mathematical papers intended for publication in the Pacific Journal of Mathematics should be in typed form or offset-reproduced, double spaced with large margins. Underline Greek letters in red, German in green, and script in blue. The first paragraph or two must be capable of being used separately as a synopsis of the entire paper. It should not contain references to the bibliography. Manuscripts, in duplicate if possible, may be sent to any one of the four editors. All other communications to the editors should be addressed to the managing editor, Richard Arens, University of California, Los Angeles, California 90024.

Each author of each article receives 50 reprints free of charge; additional copies may be obtained at cost in multiples of 50 .

The Pacific Journal of Mathematics is published monthly. Effective with Volume 16 the price per volume (3 numbers) is $\$ 8.00$; single issues, $\$ 3.00$. Special price for current issues to individual faculty members of supporting institutions and to individual members of the American Mathematical Society: $\$ 4.00$ per volume; single issues $\$ 1.50$. Back numbers are available.

Subscriptions, orders for back numbers, and changes of address should be sent to Pacific Journal of Mathematics, 103 Highland Boulevard, Berkeley 8, California.

Printed at Kokusai Bunken Insatsusha (International Academic Printing Co., Ltd.), 7-17, Fujimi 2-chome, Chiyoda-ku, Tokyo, Japan.

PUBLISHED BY PACIFIC JOURNAL OF MATHEMATICS, A NON-PROFIT CORPORATION

The Supporting Institutions listed above contribute to the cost of publication of this Journal, but they are not owners of publishers and have no responsibility for its content or policies. 


\section{Pacific Journal of Mathematics \\ Vol. 25, No. $2 \quad$ October, 1968}

Martin Aigner, On the tetrahedral graph ..................... 219

Gregory Frank Bachelis, Homomorphisms of annihilator Banach

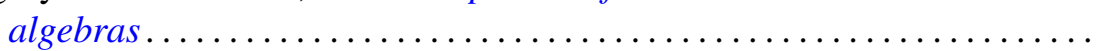

Phillip Alan Griffith, Transitive and fully transitive primary abelian groups.......................................... 249

Benjamin Rigler Halpern, Fixed points for iterates . . . . . . . . . . . . . 255

James Edgar Keesling, Mappings and dimension in general metric spaces ......................................... 277

$\mathrm{Al}$ (Allen Frederick) Kelley, Jr., Invariance for linear systems of ordinary differential equations ................................ 289

Hayri Korezlioglu, Reproducing kernels in separable Hilbert spaces . . . . . 305

Gerson Louis Levin and Wolmer Vasconcelos, Homological dimensions and Macaulay rings ................................. 315

Leo Sario and Mitsuru Nakai, Point norms in the construction of harmonic

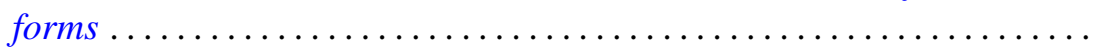

Barbara Osofsky, Noncommutative rings whose cyclic modules have cyclic injective hulls ..................................... 331

Newton Tenney Peck, Extreme points and dimension theory........... 341

Jack Segal, Quasi dimension type. II. Types in 1-dimensional spaces ...... 353

Michael Schilder, Expected values of functionals with respect to the Ito distribution ...

Grigorios Tsagas, A Riemannian space with strictly positive sectional curvature

John Alexander Williamson, Random walks and Riesz kernels . . 